\title{
Differences in Academic Achievement of Information and Communication Engineering and Counseling Psychology Students According to MBTI Personality Type
}

\author{
Seung-Ah Jung ${ }^{1}$, Young-Suk Shin ${ }^{2}$ \\ ${ }^{1}$ Professor, Division of Counseling Psychology, Chosun University, South Korea, jsa@chosun.ac.kr \\ ${ }^{2}$ Professor, Department of Information and Communication Engineering, Chosun University, \\ SouthKorea,ysshin@chosun.ac.kr \\ Corresponding author: Young-Suk Shin
}

\begin{abstract}
This study aims to find which personality types of students in Information and Communication Engineering(ICE) and Counseling Psychology(CP) majors show better academic performance. To this end, the differences between the final grades and MBTI results of the 114 ICE students taking up 'Programming Language and Practice' course and $96 \mathrm{CP}$ students taking up 'Abnormal Psychology' course, both from C university at G metropolitan city, were compared and analyzed. Descriptive statistical analysis was performed for the frequency and ratio of personality types by department, and t-test and one-way ANOVA were used to determine the average difference in academic achievement according to each department's personality type, respectively. The main results derived from the analysis are as follows. First, according to the distribution of personality types by department, students in the ICE department have significantly higher S and lower N types than those in the CP Department. The T types were higher as well in ICE department, but there was no difference in F types. Second, according to the difference between personality type and academic performance, ICE students have significantly higher academic performance than those who do not prefer I (introspective), $\mathrm{S}$ (sensitivity), and J (judgment type) types among the four personality dimensions. But there was no particular relationship between the personality type and academic achievement among CP students. Third, according to a separate analysis of ICE students, SJ type performance was the best among the four preferred indicators, and regression analysis showed that having type $\mathrm{J}$ had the greatest influence on the difference in grades. The results of this study showed that there are differences in the personality characteristics of students entering engineering and humanities and social sciences, and that there may be differences in academic achievement according to such differences. Specifically, in the case of the Department of Information and Communication Engineering, it is necessary to improve the educational method that considers the intuitive students, who are the most vulnerable to academic achievement.
\end{abstract}

Keywords: MBTI Personality Type, Programming, Academic Achievement, Correlation

\section{Introduction}

Currently, we are on the era of the 4th industrial revolution. If the 3rd industrial revolution was a world of people who handle online and computers well based on data, the 4th industrial revolution is changing into a world of people who can handle reality and virtuality based on algorithms. Gartner Group, a global market research institute, mentioned resiliency delivery as one of the three themes

Received: September 25, 2021; $1^{\text {st }}$ Review Result: November 12, 2021; $2^{\text {nd }}$ Review Result: December 27, 2021 Accepted: January 29, 2022 
(people centricity, location independence, and resilient delivery) of 'Gartner Top Strategic technology Trends for 2021' that will lead the Information Technology(IT) industry after 2021[1]. The rapid change that is coming due to the COVID-19 has raised the response to 'volatility' as a key business pointer. As technologies to respond to crises in a timely manner, intelligent configurable business, artificial intelligence engineering, and hyper-automation technologies were announced. In order to quickly adapt to the situation and reconstruct the existing one, it requires more insight through data and analysis, and the core technology of this intelligent decision is based on artificial intelligence technology.

The core of artificial intelligence technology consists of 'creativity' with flexibility that transcends fixed frameworks and connectivity that connects various entities with imagination and ideas with the power of software. Creativity can be enriched with content by combining it with other academic fields. It is expected to be strengthened through a combination with humanities, which explores human thought and culture, such as literature, history, linguistics, psychology, philosophy, theology, archaeology, and art. Such soft power is expected to provide a new growth engine to the rapidly changing industrial ecosystem. Recently, interest in software implementation has increased, and the programming craze is blowing. The ultimate goal of programming is to correctly solve a given problem. For this, logical thinking ability and thinking power for problem solving are required. In the coming age of artificial intelligence, programming education will emerge as a basic and essential element. In order to prepare for this, programming education is also urgently required to have a customized teaching method that considers the interests of learners. Such teaching methods should be considered so that not only engineering students but also learners in all other fields of study can receive the same benefits. Customized teaching method diversifies the teaching method by analyzing the learning style of learners. In order to achieve this goal, it is judged that the analysis of the learner's personality type should be preceded.

For the analysis of personality types, based on the psychological type theory of Jung[2], Myers-Briggs Type Indicator (MBTI) developed by Myers and MaCaulley[3] as a test tool to reveal different personalities exists. Myers[4], in his reference to personality type and learning style, said that intuition type students and sensory type students have different interests in subjects, and even in subjects with the same interest, interest levels are different according to sub-fields. Intuitive students are more interested in theories and laws of 'why this happens?', whereas sensory students are more interested in practical applications such as "what, how". In reality, given that most subjects have both theoretical and practical aspects, if a teaching method that emphasizes only one aspect is used, there is a risk of decline in interest among students who have other aspects. Therefore, future teaching methods to solve these problems require an attempt to more actively explore aspects that students have strong interest in. So, how can students explore their interests? In a study on career maturity and career interest according to learning personality types for middle school, high school, and university students, Kim Man-Kwon and Lee EunJeong[5] reported that career interests were very different according to the characteristics of learning personality types. This suggests that the career areas that students are interested in differ according to the type of learning personality. In the case of college students entering by selecting a major, it is presumed that their interest in the career field they are interested in and their learning style are related to some degree in the major they choose. Lee Kyung-Ah and 4 others[6] conducted a study on the relationship of learning personality types and major satisfaction on academic achievement related variables with college students. In the results of the study, among the learning personality types, the normative type used learning strategies best and had high learning motivation and academic performance, while the ideal type showed a low score on the academic achievement-related variables, indicating a significant relationship between the learning personality type and the academic achievement-related variables. In a study on mathematics learning propensity of high school students by learning type, Hwang Woon-Gu[7] found the characteristics and differences between the learning personality types in the mathematics learning method and problem-solving process. Regarding the 
academic achievement in mathematics, the average of the inquiry type and the normative type was higher than the behavior type and the ideal type among the learning personality types, and the inquiry type and the normative type showed a significant difference between the behavior type and the ideal type.

The results of previous studies showed that learning style had a close relationship with students' career interest, and that learning style had a close relationship with academic achievement. It is reported that this learning style has a high degree of congruence with the personality type[8]. Therefore, if a learning style according to an individual's personality type is first explored, based on this, a section according to the learner's style can be created and presented separately so that students can select their preferred learning method. No matter which one you choose, the grades will be the same, and some students may choose all of the multiple learning methods. In the era of the 4th industrial revolution centered on intelligence, where the possibility of application through grafting with other academic fields is enriched, it is thought that it will meet the demands of the times to expand and explore learner styles in other fields of study by expanding in a specific field of study.

In this study, the relationship between personality type and academic achievement was analyzed after performing the MBTI personality type test on students who participated in programming classes and counseling classes for a group of university students in engineering and humanities and social sciences, which are different fields of study. The structure of this paper is as follows. Chapter 2 examines the theoretical background of the analysis of the learner's personality type, and Chapter 3 describes the research method. Chapter 4 presents the research results, and Chapter 5 describes the discussions. Finally, Chapter 6 describes the conclusions and limitations of this study and future research.

\section{Theoretical Background}

\subsection{C.G.Jung's Psychological Typology and MBTI}

The question of how to classify and understand various temperament, disposition, and characteristics of humans has been a topic of interest for many scholars, regardless of East and West, long before the birth of psychology in modern times. Hippocrates, who was previously called the father of Western medicine, argued that all humans can be classified into four types (choleric, melanchoric, sanguine, phlegmatic) according to the type of humor flowing through our body. This is similar to the oriental medicine based on yin and yang theory or the 'SaSanag' medicine established by Lee Jae Ma in Korea. In psychology, the attempt to understand humans by classifying numerous human characteristics into several simple core types of sets is called "psychological typology". Most typologies of modern psychology choose an empirical method of statistically classifying and categorizing measured data, but the typology proposed by Jung was established based on his theory of human mind. Jung, who started as a psychoanalyst of the Freud school, has developed his own human typology since rejecting Freud's view of focusing on sexual energy called libido. He looked at human personality types from two main aspects. First, he looks at human personality types in terms of energy. He excluded sexual color from Freud's Libido, and considered that the 'attitude' or perspective of all humans' basic lives is determined by whether the direction of energy is directed outside or towards humans. This concept of introversionextroversion can be seen as the most well-known human personality classification method. The second is the 'functional' aspect of seeing how the mind works, and the four key functions are: thinking, feeling, sensation, and intuition, and like introversion-extroversion, these thinking-feeling and sensory-intuitive are opposed to each other. Both thinking ( $\mathrm{T}$ ) and feeling $(\mathrm{F})$ are one of the forms of judgment, and thinking differs only in that thinking is judged through a logical relationship and feeling judges the importance of the merits or values of the individual's emotions through good and bad feelings. Therefore, Jung referred to both of these functions as 'rational functions'. On the other hand, both sense(S)- 
intuition $(\mathrm{N})$ are recognition functions, in that they proceed freely and openly without attempting to evaluate or judge objects, such as thinking-feeling [9].

Myers and MaCaulley[3] added a pair of poles called judging $(\mathrm{J})$-perceiving $(\mathrm{P})$ to Jung's typology, which does not just end in theory, but actually develops into a useful evaluation tool to classify and understand various people in everyday life, which is Myers-Briggs Type Indicator (MBTI). Since it was created on this theoretical basis, MBTI first classifies humans according to which of these four opposite pole pairs they prefer. The core characteristics of personality types categorized according to these four preferred indicators are summarized in [Table 1]. In addition, the four identified preferred indicators are combined and subdivided into 16 personality types, and the characteristics of each subdivided personality type are summarized in [Table 2][10].

\subsection{Personality Type and Learning Style}

Personality types appearing in MBTI appear to show differences in the subjects already preferred in middle and high schools or in sub-fields within subjects[11][12][13]. Park Young-Mi[11] found that middle school students with ISTJ (Introversion, Sensing, Thinking, and Judging) personality types had a high preference for Math, Science, and English subjects, and students with ESFJ (Extroversion, Sensation, feeling, Judgment) personality types had a high preference for Physical Education subjects. Hong Chun-Su[12] found that students with Intuition (N) personality type had higher academic achievement than students with Sensing type (S) in Mathematics subjects for middle and high school students. It is reported that this type shows excellent grades in concepts and mathematics application areas. Also, in the study of whether math academic achievement is related to math preference, students with thinking $(\mathrm{T})$ personality type showed higher preference than students with feeling $(\mathrm{F})$ personality type[13].

According to the study of Myers and Briggs[10], the difference in learning styles between the sensory type $(\mathrm{S})$ and the intuition type $(\mathrm{N})$ is that the sensory type places importance on concrete experiences, whereas the intuitive type is interested in abstract concepts. Golay[14] created four learning types based on the four temperaments of Keirsey and Bates[15] and revealed the differences in learning methods. Practical-spontaneous learners preferred artistic experience spaces to satisfy their desire to experience, compete, and express themselves, and for conceptual-inclusive learners, they preferred small group discussion classes where personal interaction was possible. It was said that the practical-mechanical learners listen to lectures in a structured classroom and prefer repetitive learning, and that the conceptual-specific learners would benefit from scientific experiments. This suggests that there are differences in learning methods and learning environments depending on the type of learner's temperament. Lawrence[16] also observed the learning situation in the study of personality types and learning styles and reported that learners' interests, learning style preferences, and problem-solving strategies differ according to personality types. Seo Gap-Ju[8] introduced the learning type according to Golay's temperament to Korea as a concept of 'learning personality type', and practical-spontaneous learners were classified as 'action type', practical-mechanical learners as 'norm type', conceptual-specific learners as 'inquiry type', and conceptual-inclusive learners as 'ideal type', and developed as a U\&I learning personality type test.

Seo Gap-Ju[8] studied whether the four traits of MBTI (SP, SJ, NT, NF) and four temperaments learning methods (behavioral, normative, inquiry, ideal) of the U\&I have a mutual effect on academic achievement. As a result of the study, a partial but high concordance was confirmed between the MBTI four traits and the U\&I four learning personality types. In particular, as a result of checking the pair's academic achievements, where the similarity between trait and learning type is assumed, when the normative learning method was selected for SJ and SP, the NT and NF showed the highest academic achievement when the inquiry-type learning method was selected. It is said that the characteristic of the 
normative type is that after clearly understanding one stage, it moves on to the next stage, learning each stage sequentially, and preferring to study in a consistent and systematic way with repeated training. The SP trait is the same as the normative type (SJ) because it prefers to learn practical things necessary for reality rather than conceptual and abstract, but differs too because it prefers freedom, dislikes obligations or bondage, and seeks improvised motivation. Therefore, it seems that learners with SP trait can expect more improved academic achievement when they learn to submit tasks within a set deadline like normative learners and have a learning habit of consistently studying according to the suggested procedures.

[Table 1] Four Preference Indices

\begin{tabular}{|c|c|c|}
\hline$\underline{\text { Extraversion }}$ & direction of attitude or energy & $\underline{\mathbf{I}}$ ntroversion \\
\hline $\begin{array}{l}\text { The direction of energy is mainly directed to } \\
\text { people or objects in the outside world. }\end{array}$ & & $\begin{array}{l}\text { The direction of energy is primarily directed to the } \\
\text { experience or thoughts of the internal world. }\end{array}$ \\
\hline$\underline{\mathbf{S}}$ ensing & & Intuiting \\
\hline $\begin{array}{l}\text { It mainly focuses on what is perceived by the five } \\
\text { senses. }\end{array}$ & & $\begin{array}{l}\text { It mainly focuses on perceived patterns or } \\
\text { interrelational contexts. }\end{array}$ \\
\hline$\underline{\mathbf{T}}$ hinking & & $\underline{\mathbf{F}}$ eeling \\
\hline $\begin{array}{l}\text { Focusing on objectivity and fairness, conclusions } \\
\text { are made based on logical analysis. }\end{array}$ & & $\begin{array}{l}\text { Focusing on understanding and harmony, } \\
\text { conclusions are made based on subjective and } \\
\text { social values. }\end{array}$ \\
\hline$\underline{\mathbf{J}}$ udging & life styles that deals with the outside world & $\underline{\mathbf{P}}$ erceiving \\
\hline $\begin{array}{l}\text { It prefers decisions or conclusions resulting from } \\
\text { dealing with the outside world using one of the } \\
\text { judgment functions (thinking or emotion). }\end{array}$ & & $\begin{array}{l}\text { It prefers flexibility and spontaneity resulting from } \\
\text { dealing with the outside world using one of the } \\
\text { recognition functions (sense or intuition). }\end{array}$ \\
\hline
\end{tabular}

\section{J. T. Kim and H. S. Shim, MBTI From M Manual[10]}

Unlike the sensing (S) type, who prefer to receive observable factual and concrete information, the intuitive $(\mathrm{N})$ type uses imagination and inspiration rather than realistic facts to focus more on future possibilities, and without hindrance or regulation. It is said that they tend to accumulate realistic information after letting their imaginations run free[10]. Therefore, in terms of learning methods, they prefer independent and spontaneous learning, and they tend to focus deeply on things that match their values and curiosity, which is the preferred learning method of the inquiry-type (NT) learners. Therefore, it seems reasonable that NT and NF learners show the highest academic achievement when the inquiry type (NT) learning method is selected. Understanding the type of learning trait and providing the right learning method and an appropriate learning environment for learning is expected to provide the best satisfaction to learners with a customized teaching method.

\section{Method}

\subsection{Subject}

A total of 210 students, consisting of 114 ICE students taking up 'Programming Language and 
Practice' in 2017 to 2019 and 96 CP students taking up 'Abnormal Psychology' in 2018 to 2020, from $\mathrm{C}$ university in $\mathrm{G}$ metropolitan city agreed to participate in this study and responded to the survey released to them. The average age of the subjects was 19.53 and 21.41 years, respectively, and the gender distribution was higher in male students (67\% and 69 students) in the ICE department and female students ( $72 \%$ and 69 students) in the CP department.

This study was approved by the IRB in advance (Deliberation No.: 2-1041055-AB-N-01-2018-27), and the purpose and method of this study were verbally explained to the students who registered for the course, and written consent was obtained.

[Table 2] 16 Personality Types classified by MBTI

\begin{tabular}{|c|c|c|c|c|c|}
\hline & & \multicolumn{2}{|c|}{ Sensing $(\mathrm{S})$} & \multicolumn{2}{|c|}{ Intuiting(N) } \\
\hline & & Thinking(T) & Feeling(F) & Feeling(F) & Thinking(T) \\
\hline \multirow{2}{*}{ 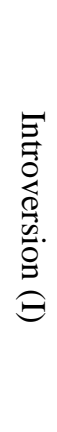 } & 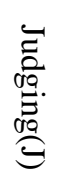 & $\begin{array}{l}\text { I. depth and focusing } \\
\text { S. sense of reality } \\
\text { T.logic and analysis } \\
\text { J.organization }\end{array}$ & $\begin{array}{l}\text { I. depth and focusing } \\
\text { S. sense of reality } \\
\text { F. warm empathy } \\
\text { J.organization }\end{array}$ & $\begin{array}{l}\text { I. depth and focusing } \\
\text { N. capture possibility } \\
\text { F. warm empathy } \\
\text { J.organization }\end{array}$ & $\begin{array}{l}\text { I. depth and focusing } \\
\text { N. capture possibility } \\
\text { T.logic and analysis } \\
\text { J.organization }\end{array}$ \\
\hline & 胥 & $\begin{array}{l}\text { I. depth and focusing } \\
\text { S. sense of reality } \\
\text { T.logic and analysis } \\
\text { P.flexible adaptation }\end{array}$ & $\begin{array}{l}\text { I. depth and focusing } \\
\text { S. sense of reality } \\
\text { F. warm empathy } \\
\text { P.flexible adaptation }\end{array}$ & $\begin{array}{l}\text { I. depth and focusing } \\
\text { N. capture possibility } \\
\text { F. warm empathy } \\
\text { P.flexible adaptation }\end{array}$ & $\begin{array}{l}\text { I. depth and focusing } \\
\text { N. capture possibility } \\
\text { T.logic and analysis } \\
\text { P.flexible adaptation }\end{array}$ \\
\hline \multirow{2}{*}{ 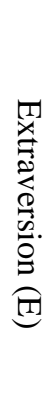 } & 兽 & $\begin{array}{l}\text { E.wide range activity } \\
\text { S. sense of reality } \\
\text { T.logic and analysis } \\
\text { P.flexible adaptation }\end{array}$ & $\begin{array}{l}\text { E.wide range activity } \\
\text { S. sense of reality } \\
\text { F. warm empathy } \\
\text { P.flexible adaptation }\end{array}$ & $\begin{array}{l}\text { E.wide range activity } \\
\text { N. capture possibility } \\
\text { F. warm empathy } \\
\text { P.flexible adaptation }\end{array}$ & $\begin{array}{l}\text { E.wide range activity } \\
\text { N. capture possibility } \\
\text { T.logic and analysis } \\
\text { P.flexible adaptation }\end{array}$ \\
\hline & 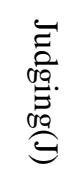 & $\begin{array}{l}\text { E.wide range activity } \\
\text { S. sense of reality } \\
\text { T.logic and analysis } \\
\text { J.organization }\end{array}$ & $\begin{array}{l}\text { E.wide range activity } \\
\text { S. sense of reality } \\
\text { F. warm empathy } \\
\text { J.organization }\end{array}$ & $\begin{array}{l}\text { E.wide range activity } \\
\text { N. capture possibility } \\
\text { F. warm empathy } \\
\text { J.organization }\end{array}$ & $\begin{array}{l}\text { E.wide range activity } \\
\text { N. capture possibility } \\
\text { T.logic and analysis } \\
\text { J.organization }\end{array}$ \\
\hline
\end{tabular}

J. T. Kim and H. S. Shim, MBTI From M Manual[10]

\subsection{Research Tools}

The personality types of participants were measured and classified by Korean version of MBTI(Form M). The Korean version of Form M type was published in 2013[10], consisting of a total of 93 questions, and each question must choose one of the two options asking for conflicting preferences across four personality preferences, and after responding, respondents themselves score the number of questions they choose. The sub-items consist of 21 questions measuring extraverted-inverted(E-I) preference, 26 questions measuring sensing-intuiting(S-N) preference, 24 questions measuring thinking-feeling(T-F) preference, and 22 questions measuring judging-perceiving (J-P) preference. This test was conducted in accordance with the guidance of the researcher in the classroom and collected at the site after obtaining written consent for the study in the first week of the course. 
The academic achievement of the subjects was measured as the final grade of the subjects they took at the end of the semester. The raw scores obtained by summing the midterm and final exams, assignment scores, and attendance scores of each subject was converted into Z scores. Each of the researchers were assigned to facilitate the 'Programming Language and Practice' and 'Abnormal Psychology' course participants in the study.

\subsection{Research Desing and Data Analysis}

Since the subject of this study, the evaluation method, and the grade point score were not calculated by an equal method, statistical comparison and verification was not conducted to examine the interaction effect between major areas. However, it is summarized in one table so that the results of examining the frequency and ratio of each personality type and the difference in grades according to the personality type by department can be compared.

The collected data were statistically analyzed with IBM SPSS (version 26) after the researchers finally reviewed the errors, no responses, and deviant responses. Descriptive statistical analysis was applied to examine the distribution of demographic characteristics or measurements of the subjects; one-way ANOVA was applied to identify the mean differences for each group; two-way ANOVA was applied to test the significance of main effects and interaction effects for each group and sub-elements of MBTI, and; stepwise regression analysis was applied to compare the influence on academic achievement by each personality subtypes classified by MBTI.

\section{Results}

\subsection{Frequency Distribution according to the Preferred Indice and Personality Types}

The distribution patterns of subjects by department and personality type are presented in [Table 3] and [Table 4].

First, looking at the distribution of preferred indice by four personality dimensions [Table 3], overall, the distribution of students from each department participating in this study was not significantly different from the sample $(\mathrm{N}=3623)$ used when MBTI type was standardized to the Korean version. However, at the J-P dimension, both the ICE and CP departments showed higher frequency of P type than the standardized sample.

As a result of verifying whether there is a difference in frequency distribution between ICE students and the CP students, there is a difference only at the S-N dimension $[\chi 2(1)=8.452, p<.01]$. Specifically, ICE students were more of type $\mathrm{S}$, but in the case of $\mathrm{CP}$, the frequency of type $\mathrm{N}$ was higher.

Looking at the distribution by 16 types of MBTI, ESFP $(15.8 \%)$ was the most common in the ICE department, which is much higher than the ratio of standardized samples (5.3\%). In the CP department, INFP $(14.6 \%)$ and ENFP (13.5\%) were the most common, which was also higher than the proportion of standardized samples $(6.5 \%$ and $8.4 \%)$.

Meanwhile, we examined whether there are differences in the distribution of students in each department by four functional types (ST, SF, NF, NT) and four trait types (SJ, SP, NF, NT), which are presented in [Table 5]. By four functional types, students in the ICE had the highest rate of sensory thinking type (ST), and students in the CP had the highest rate of intuitive feeling type (NF). By four trait types, the ratio of sensory perception type (SP) was the highest in the ICE department, and intuitive feeling type (NF) in the CP department. 


\subsection{Differences of Achievement according to Departments and Personality Types}

In order to compare detailed differences between personality type, major, and grade, t-test was conducted to see if the average difference between grades appeared for each of the four personality dimensions. As a result, in the case of students majoring in $\mathrm{CP}$, there was no difference in grades at any personality level. However, in the case of students majoring in ICE, there were significant differences in all three dimensions (E-I, N-S, and J-P) except for the thinking-feeling dimension (T-F) [Table 7]. In detail, ICE students had significantly higher grades in the case of Introverted (I) type than Extroverted $(\mathrm{N})$ type, Sensing $(\mathrm{S})$ type than Intuiting $(\mathrm{N})$ type, and Judging $(\mathrm{J})$ type than Perceiving $(\mathrm{P})$ type.

\subsection{Differences of Academic Achievement according to Personality Types: ICE Students}

Since there were differences according to personality types only in ICE students, a more detailed analysis was conducted only with their data. The ICE data were divided into four functions and four substrates and compared through a one-way ANOVA test. As a result, there was no difference in Zscores between the four functions, but there was a significant difference between the four traits [Table $8]$.

[Table 3] Frequency Distribution of MBTI 4 Dimensional Preference Index

\begin{tabular}{c|cc|cc|cc}
\hline \multirow{2}{*}{ Dept. } & \multicolumn{2}{|c|}{ ICE } & \multicolumn{2}{c|}{ CP } & \multicolumn{2}{c}{$\begin{array}{c}\text { Std. Sample* } \\
\text { N=3,623 }\end{array}$} \\
Type & Freq. & $(\%)$ & Freq. & $(\%)$ & Freq & $(\%)$ \\
\hline E & 59 & 51.8 & 42 & 43.8 & 1672 & 46.1 \\
I & 55 & 48.2 & 54 & 56.3 & 1951 & 53.9 \\
\hline S & 75 & 65.8 & 44 & 45.8 & 2199 & 60.7 \\
N & 39 & 34.2 & 52 & 54.2 & 1424 & 39.3 \\
\hline T & 50 & 43.9 & 34 & 35.4 & 1872 & 51.7 \\
F & 64 & 56.1 & 62 & 64.6 & 1751 & 48.3 \\
\hline J & 41 & 36.0 & 42 & 43.8 & 2061 & 56.9 \\
P & 73 & 64.0 & 54 & 56.3 & 160 & 43.1 \\
\hline
\end{tabular}

* MBTI Form M Sample, J. T. Kim and H. S. Shim, MBTI From M Manual[10]

[Table 4] Frequency Distribution of MBTI 16 Personality Types

\begin{tabular}{|c|c|c|c|c|c|c|}
\hline \multirow{2}{*}{$\begin{array}{l}\text { Dept. } \\
\text { Type }\end{array}$} & \multicolumn{2}{|c|}{$\begin{array}{c}\text { ICE } \\
\mathrm{N}=114\end{array}$} & \multicolumn{2}{|c|}{$\begin{array}{c}\mathrm{CP} \\
\mathrm{N}=96\end{array}$} & \multicolumn{2}{|c|}{$\begin{array}{c}\text { Std.Sample* } \\
\mathrm{N}=3,623\end{array}$} \\
\hline & Freq & $(\%)$ & Freq & $(\%)$ & Freq & $(\%)$ \\
\hline ENFJ & 4 & 3.5 & 4 & 4.2 & 125 & 3.5 \\
\hline ENFP & 9 & 7.9 & 13 & 13.5 & 304 & 8.4 \\
\hline ENTJ & 1 & 0.9 & 0 & 0.0 & 138 & 3.8 \\
\hline ENTP & 6 & 5.3 & 6 & 6.3 & 128 & 3.5 \\
\hline ESFJ & 5 & 4.4 & 6 & 6.3 & 237 & 6.6 \\
\hline ESFP & 18 & 15.8 & 5 & 5.2 & 193 & 5.3 \\
\hline ESTJ & 9 & 7.9 & 6 & 6.3 & 387 & 10.7 \\
\hline ESTP & 8 & 7.0 & 2 & 2.1 & 160 & 4.4 \\
\hline INFJ & 3 & 2.6 & 7 & 7.3 & 137 & 3.8 \\
\hline INFP & 11 & 9.6 & 14 & 14.6 & 235 & 6.5 \\
\hline INTJ & 2 & 1.8 & 3 & 3.1 & 200 & 5.5 \\
\hline
\end{tabular}




\begin{tabular}{c|cc|cc|cc}
\hline INTP & 3 & 2.6 & 5 & 5.2 & 157 & 4.3 \\
\hline ISFJ & 9 & 7.9 & 8 & 8.3 & 305 & 8.4 \\
\hline ISFP & 7 & 6.1 & 5 & 5.2 & 215 & 5.9 \\
\hline ISTJ & 8 & 7.0 & 8 & 8.3 & 532 & 14.7 \\
\hline ISTP & 11 & 9.6 & 4 & 4.2 & 170 & 4.7 \\
\hline
\end{tabular}

* MBTI Form M Sample, J. T. Kim and H. S. Shim, MBTI From M Manual[10]

[Table 5] Frequency Distribution across MBTI Function and Disposition ( ) :\%

\begin{tabular}{|c|c|c|c|c|c|c|c|c|}
\hline \multirow{2}{*}{} & \multicolumn{5}{|c|}{ Function } & \multicolumn{4}{c|}{ Trait } \\
\cline { 2 - 9 } & $\mathrm{ST}$ & $\mathrm{SF}$ & $\mathrm{NT}$ & $\mathrm{NF}$ & $\mathrm{SJ}$ & $\mathrm{SP}$ & $\mathrm{NT}$ & $\mathrm{NF}$ \\
\hline ICE & $38(33.3)$ & $37(32.5)$ & $12(10.5)$ & $27(23.7)$ & $31(27.2)$ & $44(38.6)$ & $12(10.5)$ & $27(23.7)$ \\
\hline $\mathrm{CP}$ & $20(20.8)$ & $24(25.0)$ & $14(14.6)$ & $38(39.6)$ & $29(30.2)$ & $16(16.7)$ & $13(13.5)$ & $38(39.6)$ \\
\hline total & $58(27.6)$ & $61(29.0)$ & $26(12.4)$ & $65(31.0)$ & $60(28.6)$ & $60(28.6)$ & $25(11.9)$ & $65(31.0)$ \\
\hline$\chi^{2}$ & \multicolumn{3}{|c|}{$8.895(3), \mathrm{p}<.05$} & \multicolumn{3}{|c|}{$13.592(3), \mathrm{p}<.01$} \\
\hline \multicolumn{8}{|c|}{ ICE: Information and Communication Engineering, CP: Counselling Psychology } \\
\hline
\end{tabular}

[Table 6] Differences between MBTI Personality Type

\begin{tabular}{|c|c|c|c|c|}
\hline & \multicolumn{4}{|c|}{ ICE } \\
\hline & $\mathrm{N}$ & Mean & SD & $\mathrm{t}$-value \\
\hline I & 55 & 0.241656 & 0.921 & $2.588 *$ \\
\hline $\mathrm{E}$ & 59 & -0.22527 & 0.999 & \\
\hline$S$ & 75 & 0.133393 & 0.941 & $2.029 *$ \\
\hline $\mathrm{N}$ & 39 & -0.25652 & 1.032 & \\
\hline $\mathrm{T}$ & 50 & 0.08058 & 0.992 & .769 \\
\hline $\mathrm{F}$ & 64 & -0.06295 & 0.985 & \\
\hline $\mathrm{J}$ & 41 & 0.366377 & 0.883 & $3.081 * *$ \\
\hline \multirow[t]{3}{*}{$\mathrm{P}$} & 73 & -0.20577 & 0.987 & \\
\hline & \multicolumn{4}{|c|}{$\mathrm{CP}$} \\
\hline & $\mathrm{N}$ & Mean & SD & $\mathrm{t}$-value \\
\hline I & 51 & 0.071333 & 0.996 & -.069 \\
\hline $\mathrm{E}$ & 38 & 0.085558 & 0.917 & \\
\hline$S$ & 41 & 0.019638 & 1.022 & -.523 \\
\hline $\mathrm{N}$ & 48 & 0.12675 & 0.908 & \\
\hline $\mathrm{T}$ & 30 & 0.202797 & 0.982 & .879 \\
\hline $\mathrm{F}$ & 59 & 0.013649 & 0.948 & \\
\hline $\mathrm{J}$ & 39 & 0.032899 & 1.120 & -.385 \\
\hline$P$ & 50 & 0.112122 & 0.821 & \\
\hline
\end{tabular}

[Table 7] Differences of Academic Achievement in MBTI Dispositional Type of ICE Students

\begin{tabular}{|c|c|c|c|c|c|c|c|c|c|}
\hline trait & $\mathrm{N}$ & mean & $\mathrm{SD}$ & F-value & function & $\mathrm{N}$ & Mean & $\mathrm{SD}$ & F-value \\
\hline $\mathrm{SJ} 1$ & 31 & 0.516 & 0.826 & $4.506^{* *}$ & $\mathrm{ST}$ & 38 & 0.234 & 0.921 & 1.781 \\
\hline $\mathrm{SP} 2$ & 44 & -0.136 & 0.931 & & $\mathrm{SF}$ & 37 & 0.029 & 0.962 & \\
\hline $\mathrm{NT} 3$ & 12 & -0.408 & 1.088 & & $\mathrm{NT}$ & 12 & -0.408 & 1.088 & \\
\hline
\end{tabular}




\begin{tabular}{|c|c|c|c|c|c|c|c|c|c|}
\hline NF4 & 27 & -0.189 & 1.021 & & NF & 27 & -0.189 & 1.021 & \\
\hline total & 114 & 0.000 & 0.987 & & total & 114 & 0.000 & 0.987 & \\
\hline $0 * p<001$ Sheffe $2,3,4<1$ & $* 001$
\end{tabular}

To find out specifically which trait type caused this difference, we conducted post-hoc analysis (Scheffé test). The result of this analysis showed that the students belonging to the sensing-judging (SJ) type showed significantly better academic achievement scores.

[Table 8] Comparison of Effects across 4 MBTI Personality Type in the ICE Students

\begin{tabular}{|c|c|c|c|c|c|c|c|}
\hline & $\begin{array}{c}\text { Non-standardized } \\
\text { Coefficient }\end{array}$ & $\begin{array}{c}\text { Standardized } \\
\text { Coefficient }\end{array}$ & & Sig. & \multicolumn{2}{c|}{ Collinearity Statistics } \\
\hline & $\mathrm{B}$ & $\mathrm{SE}$ & $\beta$ & $\mathrm{t}$ & $\mathrm{p}$ & tolerance & VIF \\
\hline constant & -1.204 & 0.276 & & -4.369 & 0 & & \\
\hline J:judging & 0.048 & 0.016 & 0.261 & 2.954 & 0.004 & 0.961 & 1.04 \\
\hline S:sensing & 0.034 & 0.015 & 0.199 & 2.233 & 0.028 & 0.945 & 1.058 \\
\hline I:introversion & 0.026 & 0.013 & 0.175 & 1.996 & 0.048 & 0.971 & 1.029 \\
\hline \multicolumn{7}{|c|}{ F-value(p) $=7.867(.000)$, adj.R2 $=0.154$, Dubin-Watson=2.016 } \\
\hline
\end{tabular}

The previous analysis showed that among the four dimensions, students with Introversion(I) type in the ICE department had significantly better grades (see [Table 7]). So it can be assumed that students with the personality type combined with Introverted(I), Sensing(S), and Judging(J) types would show the best academic achievement scores. To confirm this, $t$-test was conducted to see if there is a difference in academic scores between the students belonging to I-S-(T/F)-J type and the rest of the students who did not belong to the type. As a result, the prediction was confirmed[t(111) $=2.827, \mathrm{p}<.01]$.

Meanwhile, multivariate regression analysis was conducted to specifically confirm the magnitude of the relative effect size of the four dimensions of I-E, S-N, T-F, and J-P on academicperformance. Analysis results showed that the magnitude of effect on academic scores was greater in the order of judging $(\mathrm{J})$, sensing(S), and introversion(I) types. This result is presented in [Table 8]. When comparing the relative size of the standardized regression coefficient, it can be seen that whether it is judging $(\mathrm{J})$ type has a relatively more influence than whether it is sensing(S) type or introversion(I) type. However, these three personality types were not as large as $15.4 \%$ of the total variance (adjR2) that explained the total academic scores.

\section{Discussions}

The purpose of this study is to explore the personality types of college students studying different majors such as engineering and humanities in relation to its strengths or weaknesses based on academic achievement. To this end, the relationship between the personality types classified by MBTI and the academic achievement shown by students in two specific subjects was analyzed.

The main research results confirmed through the analysis their meaning and implications are summarized as follows.

First, looking at the distribution ratio of personality types by department, $\mathrm{E}$ type, $\mathrm{S}$ type, and $\mathrm{P}$ type among four personality dimension, sensing-thinking type (ST) and sensing-feeling (SF) type among functional dimension, and sensing-perceiving type (SP) among temperament dimension were higher in ICE students. In contrast, intuiting-thinking(NT) and intuiting-feeling(NF) types were higher in $\mathrm{CP}$ students. It can be seen as reflecting the personal preferences that the subjects already had before 
participating in this study, because the psychological construct measured and classified by MBTI itself measures the innate preferences of individuals. In other words, their choice of their current department can be seen as a result of the difference in personal characteristics they already have. Since the engineering subject itself is outside the individual and the psychology is internal, ICE students may be more sensing oriented and extroverted, while CP students may have more intuitive and introspected tendency.

Next, when analyzing the relationship between personality type and academic achievement, there was a difference in the achievement scores of specific major subjects according to the specific personality type. In the case of ICE students, the sensing (S) type, judging (J) type, extroversion (E) type, and the sensing-judging(SJ) type, a type combined with these traits, had the highest grades. In particular, it was found through regression analysis that whether or not type $\mathrm{J}$, not type $\mathrm{P}$ has the greatest influence on academic scores. These results are similar to the results of domestic studies targeting dental students[17] or accounting college students[18] using the same MBTI, and can be interpreted in the same context because the characteristics of the major itself are similar. In particular, accounting courses and programming courses in the ICE department have similar core cognitive functions required. It seems that the $\mathrm{J}$ type is more advantageous than the $\mathrm{P}$ type and $\mathrm{S}$ type is more advantageous than the $\mathrm{N}$ type because computer program should be written without any errors in accordance with the programming grammar constructed by a certain logic, and because it is a subject in which correct and incorrect answers can be defined and confirmed by clear standards, and the achievement scores are evaluated according to such criteria. In particular, the results of this study, which showed significantly superior performance of students belonging to the sensing- judging type ( $\mathrm{SJ}$ ) in terms of trait types, can be explained as having high similarities with those of 'normative type' learners reported in previous study [8].

However, in the case of ICE students, it is necessary to think about how to integrate and interpret previous studies that did not match the results of this study. For example, the results of this study are inconsistent with the results of foreign and domestic studies[19][20] that NT type high school students generally had higher academic achievement in all subjects or engineering students had higher grades in $\mathrm{N}$ type. These results are inconsistent with the present study because the ICE students who participated in this study had lower grades for Type $\mathrm{N}$ and higher grades for Type $\mathrm{S}$, which was at the opposite point. After reviewing representative domestic studies that explored the relationship between MBTI personality types and academic achievement, Kim Jae-Sung and Park Jong-Cheol[21] concluded that it is not possible to draw a consistent conclusion that a specific personality type affects academic performance. This discrepancy may also be related to the result that the total explanatory variance of personality type among various variables affecting grades was not very high(15.4\%), as shown in the results of the regression analysis of this study. In other words, academic achievement is a domain primarily related to intellectual function, and although personality type is related to such cognitive function, it may not be a direct and powerful factor. Since personality type may not be a variable that has a decisive influence among the total variables predicting academic performance, it may fluctuate according to various groups or situations, and may vary according to task performance style, emotional stability and control, etc. Therefore, when those major factors are combined and explained, the predictive power for academic performance can be enhanced.

On the other hand, the academic scores of CP students do not show any significant difference in any specific personality type classified under MBTI. Since the study of counseling psychology itself studies human and human psychological phenomena, it can be expected that students who prefer introverted and intuitive functions will have better achievements, but such a result was not found in this study. The CP students had a lower S-type score $[\mathrm{t}(208)=3.630, \mathrm{p}<.01]$ and a higher $\mathrm{N}$-type score than ICE students $[\mathrm{t}(208)=-3.074, \mathrm{p}<.01]$. This shows that $\mathrm{CP}$ students are a group composed of students who have a clearer preference for N-type than S-type than ICE students. Nevertheless, among the CP students, the academic sores of $\mathrm{N}$-type students were not significantly different from those of the other types. Even 
if the personality types were analyzed at any level, such as the four personality preference indicators, the four traits and functional dimensions, and the 16 personality types, there was no significant difference in scores according to the personality types in the results of the $\mathrm{CP}$ students. One hypothesis that could explain this result is that the 'Programming Languages and Practice' has more distinct attributes that people with certain personality types will achieve better grades in than subjects in the field of theory-centered psychology such as 'Abnormal Psychology'. To confirm this reasoning, a follow-up study comparing academic achievement in various subjects with a more distinct personality that is likely to interact more closely with a specific personality type will be needed. For example, in subjects such as Arts and Physical Education, where intuition is expected to be more discriminatory, or in subjects such as counseling practice that requires empathy or improvisation, students with specific personality types, such as intuition and emotion, perform better.

\section{Conclusions}

Previous studies have examined the relationship between personality types classified as MBTI and academic achievement by selecting only one specific academic field. On the other hand, this study finds its significance as it explores which personality type has strengths and weaknesses by simultaneously comparing the engineering subjects and the humanities and social science subjects, which seem to have quite different required abilities or aptitudes.

This study confirmed the following facts. First, it was revealed that the group of students who majored in information and communication engineering and psychology were distributed with different personality types. This suggests that students who choose a specific major are students with a specific personality type, and that a differentiated curriculum needs to be provided for those personality traits. Second, as a result of examining whether students with a specific personality type for each major show excellent academic achievement, the achievement of students belonging to the sensing or judging type was high only in the department of 'information and communication engineering'. This is because students with a more specific personality type may have discriminatory strengths or weaknesses in academic achievement in the case of students majoring in engineering rather than in humanities and social sciences including psychology, so consideration is required. Curriculum according to learner style is requested so that students can choose their preferred learning method.

However, since this study also compared only two specific courses, there was a limitation with which personality type is more suitable for studies in engineering and humanities and social sciences. In addition, this study has several other limitations that need to be supplemented through follow-up studies. First, the results of this study were analyzed without controlling for other variables that could affect academic achievement. Variables that can affect academic achievement can be divided into emotional (emotional stability, emotional control, self-efficacy, perseverance, etc.), cognitive (intelligence, concentration, etc.), and environmental aspects (learning environment, economic level, etc.). Although it may not be possible to fix all these factors and compare only the MBTI personality type, the fact that the intellectual ability could not be measured in advance is the important limitation of this study. However, given that the students participating in this study are students attending the same university in the same region, there is a possibility that the differences in their intellectual abilities may not be very large. Second, a student's academic achievement is likely to interact with the personality type or teaching method of the instructor in charge of the subject, and it is difficult to reach a firm conclusion only from the results of this study involving two instructors. If the results of analysis involving teachers with one personality type and various teaching methods are accumulated, it is expected that a follow-up study that establishes more specific hypotheses about the interaction effect will proceed. Third, the results of the study cannot be generalized to all university students, the sample is also limited to universities in a specific area and only majoring in engineering or humanities. There 
are various engineering fields with different detailed characteristics in the engineering field, and the same is true of the humanities and social sciences. Therefore, further research to supplement these limitations is needed in the future.

\section{Acknowledgments}

This study was supported by research funds from Chosun University, 2019.

\section{References}

[1] https://www.gartner.com/smarterwithgartner/gartner-top-strategic-technology-trends-for-2021/, Oct 19 (2020)

[2] C. G. Jung, Phychological types, Translated by M. J. Jeong, Boogle Books, pp.132-389, (2014)

[3] I. B. Myers, M. H. MaCaulley, A guide to the development and use of the Myers-Briggs type indicator, Translated by J. T. Kim, H. S. Shim, S. B. Je, Korea Psychological Examination Research Institute, pp.17-48, (1995)

[4] I. B. Myers, Gifts differing: understanding personality type, Translated by M. J. Jeong, Boogle Books, pp.139-148, (2008)

[5] M. K. Kim, E. J. Lee, Effect of Learning Style on Career Maturity and Career Interest, Korean Psychological Association Conference Materials, The Korean Psychological Association, pp.429-430, (2003), August 20-22, Seoul, Korea.

[6] K. A. Lee, N. H. Yoo, E. K. Lee, J. Y. Jeon, K. H. Lee, The relationship of academic personality types and major satisfaction on Academic achievement related variables, Korean Journal of Counseling and Psychotherapy, (2004), Vol.16, No.1, pp.107-121, UCI: G704-000523.2004.16.1.008

[7] W. G. Hwang, A Study on the Mathematical Disposition of High School Students with Types of Learning Style, Kongju University, Ph.D dissertation, pp.1-124, (2007)

[8] G. J. Seo, An Exploratory Analysis of Academic Achievement Based on MBTI Personality Preference and U\&I Learning Type, Major in Counseling Psychology, The Graduate School of Education, Sogang University, Master's thesis, pp.1-58, (2015)

[9] C. G. Jung, Psychological types, The Portable Jung, Penguin Books, pp.178-272, (1976)

[10] Katharine C. Briggs, Isabel Briggs Myers, Myers-Briggs Type Indicator : form M, Translated by J. T. Kim, H. S. Shim, ASSESTA- Online Psychological Test Center, (2013)

[11] Y. M. Park, A Study on the Character Types of Middle School Students and the Comparison and Analysis of their Academic Achievements, Major in Counseling Psychology, The Graduate School of Education, Baekseok University, Master's thesis, pp.1-44, (2008)

[12] C. S. Hong, Research on the Level of a Academic Achievement by the MBTI Type of Personality of the Middle and High school student, Department of Mathematics Education, The Graduate School of Education, Kangwon National University, Master's thesis, pp1-47, (2009)

[13] S. H. Park, The Effects of MBTI Personality Types on Mathematics Preference and Academic Achievement, Dept.of Mathematics Education, The Graduate School, Kookmin University, Master's thesis, pp.1-66, (2006)

[14] K. Golay, Learning patterns and temperament styles, Manas Systems, pp.27-50, (1982)

[15] D. Keirsey, M. Bates, Please Understand Me: Character and Temperament Types, Prometheus Nemesis Books, (1978)

[16] G. D. Lawrence, Looking at type and learning styles, Translated by H. S Shim, J. H. Lee, Y. G. Shin, J. G. Kim, M. B. Shim, Korean Psychological Examination Institute, pp.14-66, (2000)

[17] Y. H. Lee, Y. M. Lee, D. K. Kim, The relationship between Personality Types and the Academic Achievement levels 
Differences in Academic Achievement of Information and Communication Engineering and Counseling Psychology Students According to MBTI Personality Type

of Dental Students, The Korean Journal of the Human Development, (2009), Vol.16, No.1, pp.179-196, UCI: G704000726.2009.16.1.003

[18] K. B. Kim, G. Y. Shim, B. S. Lee, H. H. Oh, The Effect of Academic Achievement on Personality Type and student Learning in Principles of Accounting, Journal of Industrial Economics and Business, (2009), Vol.22, No.2, pp.579598, UCI: G704-001438.2009.22.2.018

[19] T. P. O'Brien, L. E. Bernold, D. Akroyd, Myers-Briggs type indicator and academic achievement in engineering education, International Journal of Engineering Education, (1998), Vol.14, No 5, pp.311-315, DOI: 10.1.1.455.7207

[20] E. K. Han, J. C. Kim, Relationship among the MBTI personality types and academic achievements according to gender of university students, Journal of Education Research, (2007), Vol.14, No.2, pp.149-172.

[21] J. S. Kim, J. C. Park, The Influence of the New Maritime Police Officers Personality Type on Academic Achievement and Transfer of Training, Journal of Korean Maritime Police Science, (2019), Vol.9, No.4, pp.1-43, DOI: 10.30887/jkmps.2019.9.4.001 